\title{
Determination of vancomycin and gentamicin clearance in an in vitro, closed loop dialysis system
}

\author{
Soo Min Jang ${ }^{1}$, Katie E Cardone ${ }^{1,2}$, Thomas D Nolin ${ }^{3}$, Darius L Mason ${ }^{1,2,4}$ and Darren W Grabe ${ }^{1,2,4^{*}}$
}

\begin{abstract}
Background: The purpose of this study was to evaluate the feasibility of utilizing an in-vitro, closed loop hemodialysis system as a method to assess drug clearance. Secondarily, this study tested the influence of variables (blood flow rate, dialysate flow rate, and type of filter) in the hemodialysis procedure on the clearance of vancomycin and gentamicin.

Methods: An in-vitro, closed loop hemodialysis system was constructed. The vancomycin ( $30 \mathrm{mg} / \mathrm{L}$ ) and gentamicin (25 mg/L) were added to a simulated blood system (SBS). Four conditions (C1-C4) were tested by defining the filter (Polyflux $170 \mathrm{H}$ or F180) and the blood and dialysate flow rates (BFR and DFR). All hemodialysis sessions were 3 hours in length and each condition was completed in duplicate. Dialysate effluent was collected in a 50 gallon polyethylene drum. Samples were collected (in duplicate) from the SBS and the dialysate effluent at baseline and at the end of the hemodialysis session. Samples were analyzed for vancomycin and gentamicin with an ultrahigh performance liquid chromatography/tandem mass spectrometry method.
\end{abstract}

Results: A total of eight 3-hour hemodialysis sessions were conducted. For all tested conditions (C1-C4), vancomycin was undetectable in the SBS at the end of dialysis. However, total vancomycin recovery in the dialysis effluent was $85 \pm 18 \%$, suggesting that up to $15 \%$ may have adsorbed to the dialysis filter or tubing. Gentamicin clearance from SBS was $>98 \%$ in all tested conditions. Average gentamicin recovery in the dialysate effluent was $99 \pm 15 \%$.

Conclusion: Both vancomycin and gentamicin were readily removed by high-flux hemodialysis under all conditions studied. No significant differences in drug clearance were observed between conditions used in this in vitro study. The clinical implications of changing these hemodialysis parameters are unknown.

Keywords: Hemodialysis, in vitro system, Vancomycin, Gentamicin, Clearance

\section{Background}

Pharmacokinetics are significantly altered during hemodialysis and require directed studies in this setting in order to guide drug dosing $[1,2]$. These clinical studies provide valuable information but are limited since dialysis variables (flow rates, filter selection, time on dialysis) may or may not be standardized [3-11]. Studies can be designed using one regimen with standardized blood flow

\footnotetext{
* Correspondence: darren.grabe@acphs.edu

'Department of Pharmacy Practice, Albany College of Pharmacy and Health Sciences, 106 New Scotland Avenue, Albany 12208, NY, USA

${ }^{2}$ Department of Pharmacy Practice, Albany Nephrology Pharmacy Group (ANephRx), Albany College of Pharmacy and Health Sciences, 106 New Scotland Avenue, Albany 12208, NY, USA

Full list of author information is available at the end of the article
}

rates (BFR) and dialysate flow rates (DFR), similar hemodialysis filters and similar convective (ultrafiltration) flow rates (UFR). While this type of design reduces variability and is desirable in a small sample size, it may confine application of the results to that stated hemodialysis prescription and thus the determined pharmacokinetic parameters. Studies that do not standardize the dialysis prescription lack clarity on the potential influence of those variables on drug clearance. A more comprehensive study to evaluate the impact of a change in one or more of these parameters is desirable but challenging to conduct in an in vivo design. However, these studies may be feasible in a simulated model of hemodialysis. While in vitro models of dialysis 
have been used to predict drug clearance, most have investigated the influence of changing just one variable such as the dialyzer [12,13].

This study was aimed at characterizing the clearance of vancomycin and gentamicin and the influence of changes in 3 variables (BFR, DFR and hemodialysis filters) on clearance in a closed loop in vitro dialysis system. It is hypothesized that the clearance of vancomycin and gentamicin will increase with increasing flow rates and more efficient hemodialysis filters.

\section{Methods}

\section{Study design}

This was an in vitro pharmacokinetic study of two antibiotics in a model of hemodialysis.

\section{Description of model}

A closed-loop fixed volume reservoir of a 5-L normal saline solution $(4750 \mathrm{~mL}$ reservoir $+250 \mathrm{~mL}$ tubing and dialysis membrane volume) was prepared for a simulated blood system (SBS). The normal saline had a $\mathrm{pH}$ of 5.0 and an osmolarity of $308 \mathrm{mOsmol} / \mathrm{L}$. Polyvinyl chloride tubing was used to create the SBS. The supply lines were connected from the dialysate supply [Acid (NaturaLyte Liquid Acid Concentrate $2 \mathrm{mEq} / \mathrm{L}$ potassium, $2.5 \mathrm{mEq} / \mathrm{L}$ calcium) and bicarbonate powder (NaturaLyte; Fresenius)] to the filter and from the filter into a 50 gallon plastic drum for collection of the dialysate. The system was primed with $250 \mathrm{~mL}$ of normal saline prior to initiation of the dialysis procedure and maintained at $37^{\circ} \mathrm{C}$.

Four different conditions were studied (Table 1): two sets of BFR $(400 \mathrm{~mL} / \mathrm{min}$ and $500 \mathrm{~mL} / \mathrm{min})$ and DFR $(600 \mathrm{~mL} / \mathrm{min}$ and $800 \mathrm{~mL} / \mathrm{min})$ were tested. Table 1 also outlines the characteristics of the two hemodialysis membranes that were used in the study [Polyflux $170 \mathrm{H}$ (Gambro) and the Optiflux F180 (Fresenius)]. The UFR was maintained at $300 \mathrm{~mL} / \mathrm{hr}$ to approximate the net fluid removal of one liter, to simulate a typical hemodialysis prescription, and to minimize convective solute clearance. A volumetric HD machine (model $2008 \mathrm{H}$, Fresenius USA, Walnut Creek, CA) was used to control the BFR, DFR and UFR. Each hemodialysis session was conducted for
3 hours with no interruption. The dialysate solution was flushed counter-current to SBS within the dialysis membrane at the end of the session to rinse out tubing. Each HD procedure was conducted in duplicate.

\section{Sample preparation and collection}

Vancomycin $150 \mathrm{mg}$ and gentamicin $125 \mathrm{mg}$ were injected into the SBS to achieve final concentrations of $30 \mathrm{mg} / \mathrm{L}$ and $25 \mathrm{mg} / \mathrm{L}$, respectively. Samples $(5 \mathrm{~mL})$ were collected from SBS and dialysate at 0 and $180 \mathrm{~min}$ (end of session). All spent dialysate during the simulated HD session was collected in a 50 gallon drum and mixed prior to sampling (5 mL aliquot) for vancomycin and gentamicin. Collected samples were labeled and stored at $-70^{\circ} \mathrm{C}$ until analysis. Collected samples were stored in Nalgene freezer vials and shipped in dry ice for analysis.

\section{Sample analysis}

Vancomycin and gentamicin concentrations in study samples were simultaneously determined using an ultrahigh performance liquid chromatography/tandem mass spectrometry (UHPLC-MS/MS) method with modifications of Li et al. [14] Briefly, $25 \mu \mathrm{L}$ of sample was diluted with $20 \mathrm{mM}$ pentafluoropropionic acid (PFPA, $250 \mu \mathrm{L}$ ), then injected $(10 \mu \mathrm{L})$ directly onto the LC-MS/MS. Separation was achieved using a Thermo Accela UHPLC system with a Thermo Hypersil GOLD C18 (50 X $2.1 \mathrm{~mm}, 1.9 \mu \mathrm{m})$ column, and a $5 \mathrm{mM}$ PFPA in water to $5 \mathrm{mM}$ PFPA in acetonitrile gradient. Detection and quantification of analytes was achieved with a Thermo TSQ Quantum Ultra triple quadrupole mass spectrometer via heated electrospray ionization in positive ionization mode. Selective reaction monitoring was utilized to follow precursor to product ion $\mathrm{m} / \mathrm{z}$ transitions of $724 \rightarrow 144$ for vancomycin, $450 \rightarrow 322$ for gentamicin C1a, $464 \rightarrow 322$ for gentamicin $\mathrm{C} 2+\mathrm{C} 2 \mathrm{a}, 478 \rightarrow 322$ for gentamicin $\mathrm{C} 1$, $468 \rightarrow 163$ for tobramycin (internal standard for gentamicin), and $646 \rightarrow 290$ for cefoperazone (internal standard for vancomycin). The calibration curves for the analysis ranged from $0.5 \mu \mathrm{g} / \mathrm{mL}$ (the lower limit of quantification) to $35.0 \mu \mathrm{g} / \mathrm{mL}$ for both analytes. The intra- and inter-day precision and accuracy were $\leq 12 \%$.

Table 1 Dialysis conditions tested

\begin{tabular}{|c|c|c|c|c|}
\hline Conditions & $\begin{array}{l}\text { Blood flow rate } \\
(\mathrm{mL} / \mathrm{min})\end{array}$ & Dialysate flow rate $(\mathrm{mL} / \mathrm{min})$ & Filter & Filter characteristics \\
\hline $\mathrm{C} 1$ & 400 & 600 & Polyflux (Gambro) & \multirow{2}{*}{$\begin{array}{l}\text { Surface area } 1.7 \mathrm{~m}^{2} \text {; Wall thickness } 50 \text { microns; Inner } \\
\text { diameter } 215 \text { microns; Ultrafiltration coefficient } 70^{*}\end{array}$} \\
\hline $\mathrm{C} 2$ & 500 & 800 & Polyflux (Gambro) & \\
\hline $\mathrm{C} 3$ & 400 & 600 & Optiflux F180 (Fresenius) & \multirow{2}{*}{$\begin{array}{l}\text { Surface area } 1.8 \mathrm{~m}^{2} \text {; Wall thickness } 40 \text { microns; Inner } \\
\text { diameter } 200 \text { microns; Ultrafiltration coefficient } 60^{+}\end{array}$} \\
\hline C4 & 500 & 800 & Optiflux F180 (Fresenius) & \\
\hline
\end{tabular}

*Measured with bovine blood, Hematocrit $=32 \%$, Protein $60 \mathrm{~g} / \mathrm{L}$, at $37^{\circ} \mathrm{C}$

+ Measured with in vitro bovine, Hematocrit $=32 \%$. 


\section{Data analysis}

The mean \pm standard deviation (SD) vancomycin and gentamicin concentrations were calculated for each sample. The percent change in vancomycin and gentamicin concentration from beginning to end of HD session and absolute amount of vancomycin and gentamicin eliminated were calculated. A mean loss of greater than 15\% from the SBS of the initial concentration was considered as a clinically important loss of either vancomycin or gentamicin. Drug recovery was estimated using the following mass balance equation:

Drug recovery $(m g)=\{(\mathrm{DFR})(\mathrm{t}) \times \mathrm{CD}\} \div 1000$

DFR: Dialysis flow rate ( $\mathrm{mL} / \mathrm{min})$.

t: Hemodialysis duration (minutes).

$\mathrm{C}_{\mathrm{D}}$ : The drug concentration in dialysate $(\mu \mathrm{g} / \mathrm{mL})$.

To calculate hemodialysis clearance $\left(\mathrm{CL}_{\mathrm{D}}\right)[15]$ :

$$
C L_{D}=\frac{C_{D} \times V o l_{D}}{\mathrm{~A} \times \mathrm{t}}
$$

$\mathrm{C}_{\mathrm{D}}$ : The drug concentration in dialysate $(\mu \mathrm{g} / \mathrm{mL})$.

$\mathrm{Vol}_{\mathrm{D}}$ : The total volume of dialysate collected during the dialysis time $(\mathrm{mL})$.

A: Average concentration of drug in plasma entering the dialyzer $(\mu \mathrm{g} / \mathrm{mL})$.

t: Hemodialysis duration (minutes).

Dialysis sessions were conducted in the ANephRx Core laboratory at the Albany College of Pharmacy and Health Sciences. Vancomycin and gentamicin concentrations were analyzed at the University of Pittsburgh.

\section{Statistical analysis}

Data are reported as mean \pm standard deviation. Comparisons of filters intradialytic clearances were made using the Student's t-test except for the C3 condition (Polyflux BFR $400 \mathrm{~mL} / \mathrm{min}$; DFR $600 \mathrm{~mL} / \mathrm{min}$ ) where UFR was different $(\mathrm{UFR}=250 \mathrm{~mL} / \mathrm{hr}$ ) from other conditions (UFR $=300 \mathrm{~mL} / \mathrm{hr}$ ). All statistical tests were performed as two-sided, and a $\mathrm{P}<0.05$ was considered significant.

\section{Results}

A total of eight 3-hour hemodialysis sessions were conducted. Instillation of both vancomycin and gentamicin into the SBS system resulted in a clear solution. The dialysate compartment also consisted of a clear solution. There was no visual evidence of color change in the SBS or dialysate compartments during the study period.

Table 2 outlines the drug concentrations at different time intervals (pre- and post-dialysis session) in four experimental conditions. Table 3 summarizes the quantity of vancomycin and gentamicin recovered in dialysate after a 3-hour dialysis session using the mass balance equation and the two drugs' hemodialytic clearances. The mean vancomycin hemodialysis clearances $(\mathrm{mL} / \mathrm{min}$ ) were 82.1 , $53.3,64.1$ and 47.7 respectively for conditions through $\mathrm{C} 1$ to $\mathrm{C} 4$. The mean quantity recovered in dialysate was $142.6 \pm 9.6 \mathrm{mg}$ and was undetectable in the SBS at the end of dialysis for all tested conditions (C1-C4), indicating complete removal from the SBS compartment. The mean gentamicin hemodialysis clearances $(\mathrm{mL} / \mathrm{min})$ were 58.2 , $43.5,56.7$ and 40.6 respectively for $\mathrm{C} 1$ to $\mathrm{C} 4$. The mean quantity recovered in dialysate was $135.7 \pm 8.9 \mathrm{mg}$. Drug recovery in the effluent was $85 \pm 18 \%$ for vancomycin and $99 \pm 15 \%$ for gentamicin. Vancomycin and gentamicin clearances in C2 and C4 (BFR of $500 \mathrm{~mL} / \mathrm{min}$ and DFR of $800 \mathrm{~mL} / \mathrm{min}$ ) were similar. Specifically, vancomycin clearances with Polyflux and Optiflux filters were 53.3 and $47.7 \mathrm{~mL} / \mathrm{min}$, respectively $(\mathrm{p}=0.3)$, and gentamicin clearances were 43.5 and $40.6 \mathrm{~mL} / \mathrm{min}$, respectively $(\mathrm{p}=0.6)$. Vancomycin and gentamicin clearances were also similar in C1 (BFR $400 \mathrm{~mL} / \mathrm{min}$ and DFR $600 \mathrm{~mL} / \mathrm{min}$ ) and C2 (BFR 500 and DFR $800 \mathrm{ml} / \mathrm{min}$ ) in Optiflux filter. Vancomycin clearances were 82.1 and $53.3 \mathrm{ml} / \mathrm{min}$, respectively $(\mathrm{p}=0.4)$. Gentamicin clearances in $\mathrm{C} 1$ and $\mathrm{C} 2$ were 58.2 and $43.5 \mathrm{ml} / \mathrm{min}$, respectively $(\mathrm{p}=0.1)$.

\section{Discussion}

To our knowledge, this is the first study to investigate the influence of changes in BFR, DFR, and two different filters (Polyflux and Optiflux) on vancomycin and gentamicin clearance using an in-vitro closed loop dialysis system. Interestingly, regardless of types of filter, the rate of BFR and DFR, vancomycin was undetectable in the SBS at the end of dialysis for all tested conditions (C1-C4), suggesting the drug is readily cleared by contemporary hemodialysis. Gentamicin also exhibited nearly complete removal. However, gentamicin was consistently measured in the post-dialysis SBS with the mean value of $0.52 \pm 0.01 \mathrm{ug} / \mathrm{mL}$. This was unexpected since the molecular weight of vancomycin (1485.74 $\mathrm{g} / \mathrm{mol}$ [16]) is larger than the molecular weight of gentamicin C1 (477.6 g/mol [17]).

Eighty five percent $( \pm 18 \%)$ of vancomycin was recovered in the dialysis effluent compared to $99 \pm 15 \%$ with gentamicin. Drug characteristics such as molecular size, steric hindrance, can affect the clearance, and the 15\% difference suggests that some vancomycin may have adsorbed to the dialysis filter or tubing [18]. The contribution of ultrafiltration to the overall clearance of vancomycin and gentamicin was unable to be ascertained since the ultrafiltration rate of $300 \mathrm{~mL} / \mathrm{hr}$ was held constant. The UFR may affect hemofiltration (drug elimination) [19] yet, it did not in our study. A limitation of this study was the use of normal saline instead of blood in the SBS and a one compartment model. Additionally, filters were not evaluated to verify and quantify vancomycin filter binding. The study results cannot be used to predict drug pharmacokinetics and 
Table 2 The concentration of vancomycin and gentamicin at different time interval in different conditions

\begin{tabular}{|c|c|c|c|c|c|c|c|}
\hline Condition & Filter & Sol & Time (min) & BFR (mL/min) & DFR (mL/min) & Vanco (ug/mL) & TG (ug/mL) \\
\hline \multirow[t]{4}{*}{$\mathrm{C} 1$} & Poly & SBS & 0 & 400 & 600 & $20.04 \pm 0.86$ & $26.65 \pm 1.69$ \\
\hline & Poly & SBS & 180 & 400 & 600 & BLQ & $0.51 \pm 0$ \\
\hline & Poly & Dial & 0 & 400 & 600 & BLQ & BLQ \\
\hline & Poly & Dial & 180 & 400 & 600 & $1.35 \pm 0.41$ & $1.31 \pm 0.18$ \\
\hline \multirow[t]{4}{*}{$C 2$} & Poly & SBS & 0 & 500 & 800 & $31.91 \pm 2.5$ & $35.93 \pm 0.13$ \\
\hline & Poly & SBS & 180 & 500 & 800 & BLQ & $0.53 \pm 0.02$ \\
\hline & Poly & Dial & 0 & 500 & 800 & BLQ & BLQ \\
\hline & Poly & Dial & 180 & 500 & 800 & $1.06 \pm 0.05$ & $0.99 \pm 0$ \\
\hline \multirow[t]{4}{*}{ C3 } & $\mathrm{Opt}^{*}$ & SBS & 0 & $400^{*}$ & $600^{*}$ & $23.74 \pm 5.27$ & $25.41 \pm 3.47$ \\
\hline & Opt & SBS & 180 & 400 & 600 & BLQ & $0.52 \pm 0.01$ \\
\hline & Opt & Dial & 0 & 400 & 600 & BLQ & BLQ \\
\hline & Opt & Dial & 180 & 400 & 600 & $1.20 \pm 1$ & $1.14 \pm 0.93$ \\
\hline \multirow[t]{4}{*}{$\mathrm{C} 4$} & Opt & SBS & 0 & 500 & 800 & $30.75 \pm 0.43$ & $36.97 \pm 0.18$ \\
\hline & Opt & SBS & 180 & 500 & 800 & BLQ & $0.51 \pm 0$ \\
\hline & Opt & Dial & 0 & 500 & 800 & BLQ & BLQ \\
\hline & Opt & Dial & 180 & 500 & 800 & $0.91 \pm 0.08$ & $0.94 \pm 0.15$ \\
\hline
\end{tabular}

UFR is constant at rate of $300 \mathrm{ml} / \mathrm{hr}$ except for the one condition. "UFR was $250 \mathrm{~mL} / \mathrm{hr}$. Sol: Solution; Poly: Polyflux filter; Opt: Optiflux filter; Dial: Dialysate; Vanco: Mean vancomycin concentration; TG: Mean total gentamicin concentration; BLQ: Below the lower limit of quantification.

pharmacodynamics but rather the potential for drug clearance as it pertains to changes in a dialysis prescription. This knowledge could be helpful if used in concert with available clinical data. If drug clearance can be demonstrated in such a model, clinical trials may not be necessary (presuming no active metabolites). In one study, the reliability of an in vitro model of vancomycin clearance to predict drug clearance was demonstrated [20]. There have been few in-vitro studies with other medications such as intravenous iron sucrose and dextran $[21,22]$. Pinner et al. determined that the in vitro method overestimated in vivo dialysis clearance of vancomycin and gentamicin, $27 \%$ and $17 \%$, respectively [13]. However, only one set of dialysis parameters was studied, which is an important distinction of that study compared to the present investigation [13].

\section{Conclusion}

This study aimed to characterize the clearance of vancomycin and gentamicin and the influence of changes in 3 variables (BFR, DFR and hemodialysis filters) on clearance in a closed loop in vitro dialysis system. Our study did not detect a difference in the clearance of vancomycin and gentamicin with increasing flow rates and more efficient hemodialysis filters. The concentrations of vancomycin and gentamicin in the SBS were undetectable at the conclusion of most sessions. This reflects nearly $100 \%$ clearance of both molecules in all sessions. The observed differences in the clearance of vancomycin and gentamicin between clinical studies and this study were likely due to the absence of protein binding and other volume of distribution changes not reflected in the in vitro system. Adaptation of the model to reflect in vivo characteristics may improve the performance of the system to detect differences in solute clearance. In addition, this underscores the importance of clinical pharmacokinetic and pharmacodynamic studies to validate data obtained from in vitro studies.

Table 3 Summary of the quantity of vancomycin and gentamicin using the mass balance equation and dialytic clearance

\begin{tabular}{lllllllll}
\hline Condition & Filter & Sol & BFR $(\mathbf{m L} / \mathbf{m i n})$ & DFR $(\mathrm{mL} / \mathbf{m i n})$ & Vanco $(\mathbf{m g})$ & Gent $(\mathbf{m g})$ & $\mathrm{Cl}_{\text {Vanc }}(\mathrm{mL} / \mathbf{m i n})$ & $\mathrm{Cl} \mathbf{G e n t}_{(\mathrm{mL} / \mathbf{m i n})}$ \\
\hline C1 & Poly & Dial & 400 & 600 & $147.0 \pm 44.7$ & $142.7 \pm 20$ & 82.1 & 58.2 \\
C2 & Poly & Dial & 500 & 800 & $152.9 \pm 7.2$ & $142.7 \pm 1.02$ & 53.3 & 43.5 \\
C3 & Opt & Dial & $400^{*}$ & $600^{*}$ & $131.0 \pm 108.4^{*}$ & $124.0 \pm 101.5^{*}$ & $65.3^{*}$ & $56.6^{*}$ \\
C4 & Opt & Dial & 500 & 800 & $131.9 \pm 12.3$ & $137.0 \pm 21.5$ & 47.7 & 40.6 \\
\hline
\end{tabular}

UFR is constant at rate of $300 \mathrm{ml} / \mathrm{hr}$ except for the one condition. ${ }^{*}$ UFR was $250 \mathrm{ml} / \mathrm{hr}$. Sol: Solution; Poly: Polyflux filter; Opt: Optiflux filter; Dial: Dialysate; Vanco: Vancomycin concentration; Gent: Total Gentamicin concentration; BLQ: Below the lower limit of quantification; $\mathrm{Cl}_{\mathrm{Vanc}}$ : Mean Vancomycin Clearance; $\mathrm{Cl}_{\mathrm{Gent}}$ : Mean Gentamicin clearance. 


\section{Abbreviations}

SBS: Simulated blood system; C1: Condition 1; C2: Condition 2; C3: Condition 3; C4: Condition 4; BFR: Blood flow rate; DFR: Dialysate flow rate; UFR: Ultrafiltration flow rate; HD: Hemodialysis; UHPLC: Ultra-high performance liquid chromatography; MS: Mass spectrometry; PFPA: Pentafluoropropionic acid; SD: Standard deviation.

\section{Competing interests}

The authors declare that they have no competing interests.

\section{Authors' contributions}

SC participated in the acquisition of data and interpretation of results, drafted and revised the manuscript and has given approval for the final manuscript. KC was responsible for the conception and design of the study as well as revising the manuscript in a critical fashion and has given approval for the final manuscript. TN was responsible for data analysis and interpretation as well as critically revising the original manuscript and has given approval for the final manuscript. DM was responsible for the conception and design of the study as well as revising the manuscript in a critical fashion and has given approval for the final manuscript. DG was responsible for the conception and design of the study, acquisition of data, interpretation of the data, manuscript drafting and revising and has given approval for the final manuscript. All authors agree to be accountable for al aspects of this work. They ensure that questions related to the accuracy or integrity of any part of this work are appropriately investigated and resolved. Each author has participated sufficiently in this work and takes public responsibility for appropriate portions of the content. All authors read and approved the final manuscript.

\section{Acknowledgements}

This study was supported by grant provided by Dr. George R. Bailie through the Albany College of Pharmacy and Health Sciences.

\section{Author details}

${ }^{1}$ Department of Pharmacy Practice, Albany College of Pharmacy and Health Sciences, 106 New Scotland Avenue, Albany 12208, NY, USA. ²Department of Pharmacy Practice, Albany Nephrology Pharmacy Group (ANephRx), Albany College of Pharmacy and Health Sciences, 106 New Scotland Avenue, Albany 12208, NY, USA. ${ }^{3}$ Department of Pharmacy and Therapeutics, University of Pittsburgh School of Pharmacy, 3501 Terrace Street, Pittsburgh 15261, PA, USA. ${ }^{4}$ Albany College of Pharmacy and Health Sciences, 106 New Scotland Avenue, Albany 12208, NY, USA.

Received: 26 March 2014 Accepted: 13 November 2014 Published: 20 December 2014

\section{References}

1. Olyaei AJ, Steffl $\lrcorner$ : A quantitative approach to drug dosing in chronic kidney disease. Blood Purif 2011, 31:138-145.

2. Verbeeck RK, Musuamba FP: Pharmacokinetics and dosage adjustment in patients with renal dysfunction. Eur J Clin Pharmacol 2009, 65:757-773.

3. Zoer J, Schrander-van der Meer AM, Van Dorp WT: Dosage recommendation of vancomycin during haemodialysis with highly permeable membranes. Pharm World Sci 1997, 19:191-196.

4. Scott MK, Macias WL, Kraus MA, Clark WR, Carfagna MA, Mueller BA: Effects of dialysis membrane on intradialytic vancomycin administration. Pharmacotherapy 1997, 17:256-262.

5. Vercaigne LM, Ariano RE, Zacharias JM: Bayesian pharmacokinetics of gentamicin in a haemodialysis population. Clin Pharmacokinet 2004, 43(3):205-210.

6. Stryjewski ME, Szczech LA, Benjamin DK Jr, Inrig JK, Kanafani ZA, Engemann JJ, Chu VH, Joyce MJ, Reller LB, Corey GR, Fowler VG Jr: Use of vancomycin or first-generation cephalosporins for the treatment of hemodialysis-dependent patients with Methicillin-Susceptible Staphylococcus aureus bacteremia. Clin Infect Dis 2007, 44:190-196.

7. Pai $A B$, Pai MP: Vancomycin dosing in high flux hemodialysis: a limited-sampling algorithm. Am J Health Syst Pharm 2004, 61:1812-1816.

8. DeSoi CA, Sahm DF, Umans JG: Vancomycin elimination during high-flux hemodialysis: kinetic model and comparison of four membranes. Am J Kidney Dis 1992, 20:354-360.
9. Foote EF, Dreitlein WB, Steward CA, Kapoian T, Walker JA, Sherman RA: Pharmacokinetics of vancomycin when administered during high flux hemodialysis. Clin Nephrol 1998, 50:51-55.

10. Sowinski KM, Magner SJ, Lucksiri A, Scott MK, Hamburge RJ, Mueller BA: Influence of hemodialysis on gentamicin pharmacokinetics, removal during hemodialysis, and recommended dosing. Clin J Am Soc Nephrol 2008, 3:355-361.

11. Teigen MM, Duffull $S$, Dang $L$, Johnson DW: Dosing of gentamicin in patients with end-stage renal disease receiving hemodialysis. J Clin Pharmacol 2006, 46:1259-1267.

12. Mac-Kay MV, Fernandez IP, Herrera CJ, Sancez BJ: An in vitro study of the influence of a drug's molecular weight on its overall (Clt), diffusive (Cld) and convective $(\mathrm{Clc})$ clearance through dialyzers. Biopharm Drug Dispos 1995, 16:23-35.

13. Pinner NA, Canada RB, Broyles JE, Hudson JQ: Evaluation of vancomycin and gentamicin dialysis clearance using in vivo and in vitro systems. Ren Fail 2012, 34:703-707.

14. Li B, Van Schepdael A, Hoogmartens J, Adams E: Mass spectrometric characterization of gentamicin components separated by the new European Pharmacopoeia method. J Pharm Biomed Anal 2011, 55:78-84.

15. Atkinson AJ Jr, Umans JG: Pharmacokinetic studies in hemodialysis patients. Clin Pharmacol Ther 2009, 86:548-552.

16. Vancomycin hydrochloride [package insert]. Lake Forest (IL): Hospira, Inc; 2012.

17. Gentamicin solution [package insert]. Saint Louis (MO): SIGMA; 2012.

18. Keller F, Wilms H, Schultze F, Offerman G, Molzahn M: Effect of plasma protein binding, volume of distribution and molecular weight on the fraction of drugs eliminated by hemodialysis. Clin Nephrol 1983, 19:201-205.

19. Bressolle F: Clinical pharmacokinetics during continuous haemofiltration. Clin Pharmacokinet 1994, 26:458-471.

20. Hudson JQ, Comstock TJ, Feldman GM: Evaluation of an in vitro dialysis system to predict drug removal. Nephrol Dial Transplant 2004, 19:400-405.

21. Manley HJ, Grabe DW: Determination of iron sucrose (venofer) or iron dextran (DexFerrum) removal by hemodialysis: an in-vitro study. BMC Nephrol 2004, 5:1

22. Hatton RC, Portales IT, Finlay A, Ross EA: Removal of iron dextran by hemodialysis: an in vitro study. Am J Kidney Dis 1995, 26:327-330.

doi:10.1186/1471-2369-15-204

Cite this article as: Jang et al:: Determination of vancomycin and gentamicin clearance in an in vitro, closed loop dialysis system. BMC Nephrology 2014 15:204.

\section{Submit your next manuscript to BioMed Central and take full advantage of:}

- Convenient online submission

- Thorough peer review

- No space constraints or color figure charges

- Immediate publication on acceptance

- Inclusion in PubMed, CAS, Scopus and Google Scholar

- Research which is freely available for redistribution 